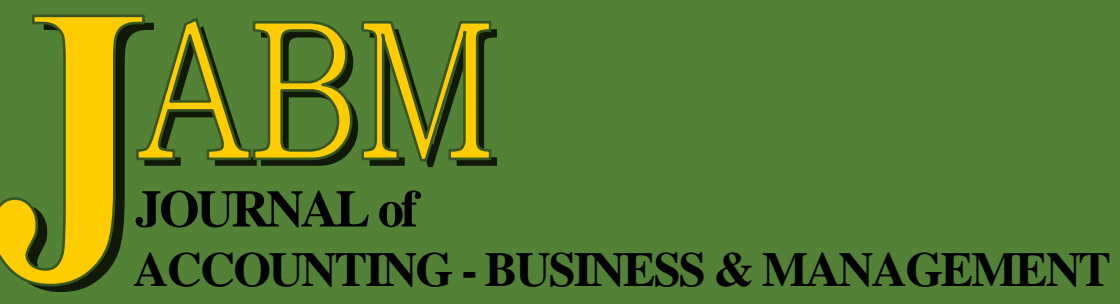

Confidence Crisis in the Application of Cloud Computing in the Industrial Companies in Jordan a Field Study

Abdullah Mohammed Al-Zoubi and Ibtissam Al-Masaiid

Comparative Analysis on Corporate Disclosure Practices of Listed Companies in ASEAN-5 after the Adoption of the Renewal Regional Disclosure Standards

Nunthapin Chantachaimongkol and Shuwen Chen

Capital Structure, Ownership Structure and Corporate Governance of SMEs in Ghana

Ibrahim Anyass Ahmed

The Tax Cuts and Jobs Act and the Middle Class

Deborah Combs and Brian Nichols

The Locus of Innovation: A Literature Review

Yongliang Stanley Han 
Journal of Accounting - Business \& Management vol. 26 no. 1 (2019) 1-20

\title{
Confidence Crisis in the Application of Cloud Computing in the Industrial Companies in Jordan a Field Study
}

\author{
Abdullah Mohammed Al-Zoubi* \\ Ibtissam Al-Masaiid ${ }^{\prime}$
}

\begin{abstract}
The current study aimed at determining the extent to which the industrial companies in Jordan have a confidence crisis in applying cloud computing. This crisis is divided into three different categories: a confidence crisis in programs and operations, a confidence crisis in service providers and a confidence crisis in the security and protection offered by service providers. In order to achieve the purpose of the research, a questionnaire was designed covering the three areas of confidence crisis. (120) questionnaires were distributed on a stratified random sample of (81) industrial companies in Al Hassan industrial estate in Irbid; (104) valid questionnaires were retrieved. The results of the study show that there is indeed a confidence crisis in the application of cloud computing in the Jordanian industrial companies within the three aforementioned domains. The researchers recommend that the service providers should educate on the cloud computing mechanisms and how the systems, applications and stored data are protected, so as to avoid such a confidence crisis in the industrial companies.
\end{abstract}

Keywords: confidence, cloud computing.

\section{INTRODUCTION}

Technology is constantly spreading new things to the business world. In fact, all companies and associations resort to technology as it saves time and effort and guarantees accuracy in accomplishing all tasks such as data-processing and informationreporting in a systematic way, high quality and in the desired manner. A novelty that technology provides is the so-called "cloud computing", which is spreading fast due to the advantages it offers in improving work quality and reducing the cost of infrastructures (Al-ulaymi \& Al-ulaymi, 2014). Moreover, cloud computing ensures the accessibility to databases and applications (Al-Fadl, 2016) in addition to several other advantage ${ }^{1}$. Many define cloud computing as a set of computer resources (servers, applications, etc) that are available to users upon request "on-demand" via the internet ${ }^{2}$ in order to accomplish and improve administrative, accounting and other tasks that the companies require.

Accounting-related tasks are crucial to the companies' welfare. Such tasks include revenues, expenses, financing and production, which produce very important datasets that should be treated with the utmost confidentiality and not made easily accessible. In order to perform these tasks, the enterprise must provide certain resources such as: applications, serves and infra-structure so that datasets are treated and stored in the company's website. However, cloud computing entails that data treatment and

\footnotetext{
* Al al-Bayt University, Accounting Department (Accounting Information Systems). Phone: 00962795530 950. E-mail: rf_zoubi@yahoo.com.

† Al al-Bayt University. Phone 00962 772320771. E-mail: razan@gmail.com.

1 See «the advantages of cloud computing» in the sections below.

2 See «cloud computing» in the sections below.
} 
storage are done by cloud computing service providers, which means that such data are accessible to external parties. This may well cause the company not to have confidence in the service providers for fear of having the data leaked or manipulated ${ }^{3}$.

The study objectives are formulated on the basis of the aforementioned reasons of confidence crisis. Therefore, the primary objective of the study is to investigate whether the industrial companies in Jordan have a confidence crisis with cloud computing service providers.

\section{STATEMENT OF THE PROBLEM}

Cloud computing has recently emerged in the form of computing resources and systems that are available upon request via the internet (applications, networks, storing, serves); it provides a number of inter-related computer services (Mell \& Grance, 2011, p. 2-3). These computing services are integral elements of accounting. In this regard, Zhygalova (2013) notes that cloud computing can improve the accounting operations if the companies seek to carry out such tasks using the applications, servers and storage utilities provided by external parties because the applications and datasets will be made available to users upon request via the internet whenever and wherever they are needed. However, the question at hand is whether these external parties, with all its members, applications, operations and protection systems, are trust-worthy.

The aforementioned question motivated the researchers to investigate confidence in cloud computing, which led to the inquiry about the confidence crisis in the companies' application of cloud computing in the Jordanian context.

\section{OBJECTIVES OF THE STUDY}

The primary objective of the current study is to determine whether or not the industrial companies in Jordan have a lack of trust in the application of cloud computing. The lack of trust "distrust" is referred to as "confidence crisis" in this study. In line with the previous objective, confidence crisis in the application of cloud computing is divided into three sub-sections, each constituting a sub-objective as follows:

1. Determining whether or not the industrial companies in Jordan have a confidence crisis in the program and operations offered by the service providers to apply cloud computing.

2. Determining whether or not the industrial companies in Jordan have a confidence crisis in the cloud computing service providers.

3. Determining whether or not the industrial companies in Jordan have a confidence crisis in the security and protection offered by cloud computing service providers.

\section{SIGNIFICANCE OF THE STUDY}

The current study gains significance from the fact that technology is indispensable for business improvement in any enterprise or institution. Companies are in a constant need to develop business and enter the world of technology in order to maximize the computing potentials and performance for treating and accessing to datasets and maintaining a reduced cost because cloud computing lets companies manage without the need to buy powerful equipments and servers, and it provides better performance (Sayed, 2013).

\footnotetext{
3 See «the disadvantages of cloud computing» in the sections below.
} 


\section{STUDY HYPOTHESES}

The study was built on a main hypothesis:

1. There is no confidence crisis in the application of cloud computing in the industrial companies in Jordan.

Confidence crisis is divided into three categories: confidence crisis in the program and operations, confidence crisis in the service providers and confidence crisis in the security and protection. Therefore, the study sub-hypotheses are formed as follows:

1. There is no confidence crisis in the program and operations offered by the service providers to apply cloud computing in the industrial companies in Jordan.

2. There is no confidence crisis in the cloud computing service providers in the industrial companies in Jordan.

3. There is no confidence crisis in the security and protection offered by cloud computing service providers in the industrial companies in Jordan.

\section{RESEARCH METHODOLOGY}

\subsection{Study Sample and Population}

The population of the current study consists of all the industrial companies in Al-Hassan industrial estate in Irbid, which are 148 companies divided into 10 industrial sectors (Office of Jordan Industrial Estates Corporation, 2017). The sample of the study consists of 81 companies chosen on the basis of stratified random sampling, considering that each industrial sector is a group. The number of companies in each group was determined in accordance with the total number of companies and the number of companies in each group. The random sampling from each group is as follows:

Table 1

Numbers of Study Sample and Population

\begin{tabular}{|c|c|c|c|c|}
\hline $\begin{array}{l}\text { Num- } \\
\text { Ber }\end{array}$ & Industrial Sectors & $\begin{array}{l}\text { Number of } \\
\text { Companies }\end{array}$ & $\begin{array}{l}\text { Percent- } \\
\text { age }\end{array}$ & $\begin{array}{c}\text { Sample } \\
\text { Size }\end{array}$ \\
\hline 1. & Food industry & 33 & 0.223 & 18 \\
\hline 2. & Textile and cotton industry & 39 & 0.263 & 21 \\
\hline 3. & Pharmaceutical industry & 11 & 0.074 & 6 \\
\hline 4. & Plastic and rubber industry & 17 & 0.115 & 9 \\
\hline 5. & Chemical industry & 14 & 0.094 & 8 \\
\hline 6. & Printing, paper and packaging & 4 & 0.027 & 2 \\
\hline 7. & Engineering industry (metal \& electric) & 22 & 0.149 & 12 \\
\hline 8. & Furniture, kitchen and doors industry & 2 & 0.014 & 1 \\
\hline 9. & Leather industry & 5 & 0.034 & 3 \\
\hline 10. & Construction industry & 1 & 0.007 & 1 \\
\hline & Total & 148 & 1 & 81 \\
\hline
\end{tabular}

120 questionnaires were distributed on the Chief Financial Officers (CFO's) and the Assistant Financial Directors (AFD's). 104 valid questionnaires were retrieved.

\subsection{Data Collection Techniques}

The data and information needed for the current research were collected in two techniques in accordance with the target information, as follows:

1) Books, Journal and Articles: these were used in order to get the needed information for the theoretical aspect of this study.

2) The questionnaire: the questionnaire consists of two parts: 
a) Sample personal background: the information in this section contains four aspects as illustrated in the second part of the results.

b) The study fields: the fields of the current study were divided into three main fields, each consists of one element of cloud computing Confidence Crisis. The three fields contain 18 items distributed equally across the three fields as illustrated in the third part of the results.

\subsection{Statistical Techniques} follows:

The current study makes use of several statistical tests provided by SPSS as

1) Cronbach's Alpha: in order to measure the research instrument's reliability.

2) Kolmogorov Smirnov (KS Test): in order to test the natural distribution of data.

3) Frequencies and Percentages.

4) Descriptive Statistics: means and standard deviations.

5) One-Sample T-test.

6) Independent-Samples T-Test.

7) One-Way ANOVA.

These tests will be outlined in the results section.

\section{CLOUD COMPUTING}

There are many definitions of cloud computing. Some scholars consider it as a new form of computing that includes a group of servers, networks, applications and resources in order to facilitate the sharing of services and resources via the internet instead of having them on local servers or personal computers (Kaushik \& Kumar, 2013). In the same view, Sayed (2013, p. 17) considers cloud computing to be a technique that offers computer resources in the form of services that give access to users via the internet "the cloud" without the need to have expertise or knowledge or even control of the supporting infra-structures. On the other hand, Romney and Steinbart (2012) define cloud computing as a process of purchasing program and storage from a third-party "service provider" by payment or on the pay-for-use payment basis. The service providers use the virtual simulation technique to provide the access of several clients to the cloud simultaneously. This enables the institutions to reduce the overall cost of information technology.

Sharif et al. (2013) state that cloud computing is a technique that provides technological services in data-centers referred to as "clouds" using program and internet hardware. The user can transfer the process of data-treatment from his personal computer to the serving computers over the internet and uses it in any place and store their data with big storage capacities. The data is administered by the serviceproviders at a cost.

Qurayqaa (2014) elaborates on the concept of cloud computing by dividing it into two parts: the cloud, which is a set of computers and servers that are accessible via the internet in any place; the cloud computing, which is the transfer of outputs into services by which the operations of data-processing and storage spaces are transferred to this cloud. 


\subsection{The Advantages of Cloud Computing}

Cloud computing has a wide-range of long-term advantages. It is not a mere technical resolution or a server that has been stored elsewhere but rather a form of computing that helps in:

1) Improving the work performance in a way that positively affects business.

2) Reducing the cost of infra-structure (Al-ulaymi \& Al-ulaymi 2014, p. 7).

3) Better-achieving success, innovation and competition (Aljabre, 2012, p. 238).

4) Enhancing profitability due to the easy maintenance and resources reassessment (Hsu \& Lin, 2016, p. 791).

5) Expansion of service and enhancing the flexibility of resources (Hurwitz et al., 2010).

6) Creating easy access to services, databases and applications by the service user in the place and time desired because the data is stored in the servers of the service providers and not in personal computers (Al-Fadl, 2016).

7) Increasing the storage capacity to save files.

8) Time-saving (Bansode \& Pujar, 2012).

9) Getting access to a large number of applications without the need to register, purchase, install or download them (Turab et al., 2013).

\subsection{The Disadvantages of Cloud Computing}

Despite the numerous advantages of cloud computing, this service is not without shortcomings. In fact, there are several disadvantages, among which are the following:

1) Security and protection concerns

Users of cloud computing are reluctant to put their files and data in the servers of the service providing company. These users are concerned with the potential of having their data hacked by other parties (Saleem, 2016). Therefore, the cloud computing service provider undertakes the task of providing protection for the data and providing high-quality networking, servers and applications in order to immune the data against hacking (Bhour, 2016). Moreover, the transfer from regular data-processing to cloud computing makes users lose control over data-management and applications within the Cloud (Ren et al., 2012).

2) Confidence

The biggest challenge that cloud computing faces is the issue of confidence. It definitely is the prime motivator/inhibitor of the adoption of cloud computing (Mohammed, 2011). This is due to the lack of appropriate procedures and policies ensuring the protection and control of data (Pawar \& Udgir, 2016). Furthermore, the use of cloud computing puts the user in constant concern about the trust-worthiness of security and protection measures set by the service providers to prevent unauthorized access (Sun et al., 2011). In addition, internet disconnection is one of the main reasons this service is not trusted because it is completely dependent on the internet (Hussein \& Mohamed, 2015). The issue of availability of resources and application can also decrease the level of confidence that users have towards cloud computing (Zissis \& Lekkas, 2012). It should be noted that the lack of confidence in the protection of resources can negatively impact the competitive capacity of the company in comparison with the other companies (Hashemi, 2013).

\section{REVIEW OF THE RELATED LITERATURE}

The subject of cloud computing has spilled a lot of ink in the literature due to its importance. This section presents a review of the literature related to the issue of confidence in the application of cloud computing. Most of the studies done in this 
regard note that the lack of trust in the security and protection that the cloud computing offers is a primary motivator behind the refraining from adopting it. Nevertheless, Al-Fadl (2016) notes that the adoption of cloud computing by users in the field of banking is totally safe for the bank data.

8.1. The Study of Bhour (2016) under the Title: "The Presence of Factors Influencing the Adoption and Application of Cloud Computing in the Government Institution from the Higher Management Perspective".

This study aimed at investigating the factors influencing the adoption and application of cloud computing from the perspective of higher management. The sample for this study consisted of the ministry delegates and their assistants and the general managers working in the government ministries in the district of Gaza in Palestine. 170 questionnaires were distributed; 117 of which were retrieved for analysis.

The study concluded that there are many factors influencing the adoption and application of cloud computing in these sectors; the most paramount of which are: the availability of technological infra-structure, confidentiality and security in the storage of data, transfer strategies, organizational support. The study also concluded that cloud computing should be promoted through the advertisement campaigns, workshops, conferences...etc.

8.2. The Study of Al-Fadl (2016) under the Title: "The Efficiency of Cloud Computing in Supporting Banking Databases".

This study aimed at identifying the aspects of banking that can be supported by cloud computing, and highlighting the advantages and disadvantages thereof. The study also aimed at determining the level of acceptance that cloud computing receives in the Iraqi banks. The sample of the study consisted of the specialists in the information department in the Iraqi banking sectors. A target sample was chosen consisting of 32 members who received the study questionnaire.

The study concluded that the operating systems, applications and hardware, being integral elements of cloud computing infra-structure, can help support the banking databases and increases the efficiency of many daily procedures involving banking databases. The study also concluded that cloud computing helps create an atmosphere of creativity and practical efficiency due to the easy access to information through the banking databases. The study recommended the initiation of scientific plans to apply the cloud computing in the banking sectors. This involves the subscription in international websites that offer cloud computing services in order to have a good understanding of the types and nature of potential services that can be offered to the Iraqi banking sectors.

\subsection{The Study of Elena and Johnson (2015) under the Title: "Factors Influencing Risk Acceptance of Cloud Computing Services in the UK Government".}

This study aimed at investigating the factors influencing risk acceptance of cloud computing services in the UK government. The sample of the study consisted of specialists in the field of information technology in the government institutions in the UK. The data was collected through the semi-structured interviews with 24 specialists in the field of information technology in the government institutions in the UK.

The study concluded that there are many factors influencing risk acceptance of cloud computing in the UK government institutions including: social risk; such as tarnishing the institutions' reputation in case the datasets are leaked or manipulated. Financial risks; such as the extra-cost caused by adopting the cloud computing. Security risks; such as the loss of privacy and confidentiality of the data and the possibility of 
unauthorized access in addition, the security measures at the level of storage, the control of datasets by the service providers, the technical glitches caused by prospective internet disconnections, the lack of confidence in the quality of cloud computing services.

The study recommended that cloud computing should provide exhaustive information about the protection and security measures and policies in order to safeguard the datasets from potential damage, manipulation or loss.

8.4. The Study of Majhi et al. (2015) under the Title: "Awareness and Usage of Cloud Computing Application among LIS Professionals: A Case Study of 17 Indian University Libraries".

This study aimed at investigating the degree to which LIS professionals are aware of the use of cloud computing, and the aim behind using it in libraries, and the most wildly used cloud computing applications, and finally investigating obstacles facing LIS professionals when using the applications of cloud computing. The population of the study consisted of all librarians, deputy librarians, assistant librarians and library technical assistants in the Indian universities (17 universities). 56 questionnaires were distributed on the sample outlined previously.

The study concluded that the library professionals are fully aware of the importance of cloud computing in the field. Moreover, the study concluded that many librarians use the cloud computing application for personal purposes. A final result of the study was the fact that lack of awareness and confidence in cloud computing are major factors influencing the choice of not adopting it.

8.5. The Study of Hashim and Hassan (2015) under the Titles: "Factors that Influence the Users' Adoption of Cloud Computing Services at Iraqi Universities: An Empirical Study".

The study aimed at investigating the factors that influence the users' adoption of cloud computing services at the Iraqi universities. The population of the study consisted of students, teachers and administrators in the Iraqi universities. 312 questionnaires were retrieved for analysis.

The study concluded that there are many factors influencing the adoption of cloud computing including: the expected time and effort, social influence, security and protection, etc. The study recommended that other research studies be conducted in order to better-identify the benefits of cloud computing, the challenge facing it and its usages in the developing countries in general and in Iraq in specific.

8.6. The Study of Alhammadi et al. (2015) under the Title: "The Determinants of Cloud Computing Adoption in Saudi Arabia".

This study aimed at investigating the factors that influence the adoption of cloud computing in the private and public sectors in Saudi Arabia. 43 questionnaires were distributed to the institution of the government sectors and 38 to the institutions of the private sectors, which gives a total of 103 retrieved questionnaires.

The study concluded that there are some statistically significant factors influencing the adoption of cloud computing in the two sectors including: security concerns, institutions readiness to adopt it, the support of higher management, the institutions' state of affairs, government support and compatibility.

8.7. The Study of Tarmidi et al. (2014) under the Title: "Cloud Computing Awareness and Adoption among Accounting Practitioners in Malaysia".

This study aimed at investigating the level of awareness of accounting practitioners in the audit and commercial fields among the small and medium companies about cloud computing. The sample of this study consists of all bachelor 
students of accounting who underwent industrial training. 500 questionnaires were randomly distributed on the sample; 329 of which were retrieved for analysis.

The study concluded that one third of the sample are aware of cloud computing and its benefits as a time and effort-saving tool. The two thirds are not fully aware of its benefits due the security concerns. The study recommended that more studies should be done on the adoption reasons and the adoption process of cloud computing as well as the implementation thereof and the reduced costs resulting from such implementation.

8.8. The Study of Budniks and Didenko (2014) under the Title: "Factors Determining Application of Cloud Computing Services in Latvian SMEs".

This study aimed at investigating the factors influencing the entrepreneurs' decision-making about the adoption and application of cloud computing in small and medium companies in Latvia Republic. The population of this study consisted of employees which hold at least middle ranking managers in these companies. 150 questionnaires were distributed on these employees.

The study concluded that cloud computing is used by a small fraction of the surveyed companies. Moreover, the results showed that there is a positive trend towards the development of cloud computing by the service providers as the results show that there is an investment of sufficient financial resources to develop the service.

8.9. The Study of Jelonek and Wyslocka (2014) under the Title: "Barriers to the Development of Cloud Computing Adoption and Usage in SMEs in Poland".

This study aimed at investigating the obstacles preventing the small and medium companies' managers in Poland from using cloud computing. The study sample consisted of 134 companies from the transformative industries, trade and service sectors. The primary data was collected via the online questionnaires, which were distributed through the emails of these companies.

The study concluded that there are several reasons inhibiting the use and application of cloud computing in these companies including: lack of confidence in data, difficult access to data and uneasy transfer of data from one service provider to another, loss of control over data, lack of security and protection of data, in addition to other legal issues in case of dispute with the service provider.

8.10. The Study of Alkhater et al. (2014) under the Title: "Factors Influencing an Organization's Intention to Adopt Cloud Computing in Saudi Arabia".

This study aimed at identifying the factors that affect the organisations' intention to use cloud computing. The data for this study was collected using semi-structured interviews with 20 informants who are IT managers and IT heads of departments with at least five years of experience in 20 companies in Saudi Arabic in different sectors (industry, engineering and energy).

The study concluded that there are several factors influencing the organizations' intention to adopt cloud computing including: security, privacy, confidence, compliance with regulations, compatibility and the physical location.

8.11. The Study of Gupta et al. (2013) under the Title: “The Usage and Adoption of Cloud Computing by Small and Medium Businesses".

This study aimed at identifying the factors influencing the usage and adoption of cloud computing in the small and medium-sized companies in Malaysia, India and the US. The population of the study consisted of all Information Technology employees in these companies. The number of the retrieved valid questionnaires is 211 . 
The study concluded that the cost-reduction, easy usage, security and privacy have a positive impact on the usage and adoption of cloud computing. Moreover, the study showed that the confidence in the service providers does not have a significant positive impact on the usage and adoption of cloud computing in the small and medium-sized companies. The study recommended that other studies be conducted considering other variables that are likely to affect the usage and adoption of cloud computing.

8.12. The Study of Abid et al. (2012) under the Title: "Cloud Computing: A General User's Perception and Security Issues at Universities of Faisalabad, Pakistan".

The study aimed at having a deeper understanding about the users' general perception of cloud computing, and the security issues that come along using it. The population of this study consisted of IT administration and IT staff at four local universities in Faisalabad in Pakistan. A number of questionnaires were distributed on the sample; 50 of which were retrieved for analysis.

The study concluded that the majority of informants are familiar with cloud computing, and that a small fraction of them do not have a clear understanding of it due to the lack of resources. The informants reported that there are many security risks due to the fact that university projects datasets may contain confidential data that is prone to harm when using cloud computing. Another major finding of this researcher was the fact that some universities refrain from adopting cloud computing due to the costs of this service as they do not have sufficient budget to bear its costs. The study recommends that the IT administrators undergo training and workshops in order to shed light on the importance of cloud computing, and that a model of the cloud be made in accordance with the requirements of the IT administrators at the Pakistani universities.

\subsection{The Study of Chen (2009) under the Title: "A Feasibility Study of the Adoption of Cloud Computing in the Development of Information Systems".}

The study aimed at investigating cloud computing, its pros and cons as well as the obstacles inhibiting its implementation in the Taiwanese organizations. In addition, the study aimed at understanding the factors that affect the adoption of cloud computing in these organizations. The population of this study consisted of the IT professionals in ten organizations in Taiwan. The data was collected through the indepth interview approach.

The study concluded that there are several factors influencing the adoption of cloud computing in the Taiwanese organizations such as: lack of extensive understanding of cloud computing, the lack of innovative models for the Taiwanese enterprises, the insufficient effort of service providers to promote the adoption of cloud computing, the incentive scheme set by the government and officials to accelerate the adoption of cloud computing. The study recommended that the feasibility of the adoption of cloud computing should be investigated by focusing on the comparison of IT service providers' policies and strategies so that to understand the factors that influence the adoption of cloud computing. 


\section{RESULTS}

The results of the current study will be outlined in five parts as follows:

\section{Part One: Internal Reliability and Test for Normality}

1) Internal Reliability: the analysis of reliability in this research was conducted using the cronbach's alpha test of reliability, which gave a value of $73 \%$. This shows that there is a significant level of internal reliability in the questionnaire constructs and items.

2) Test of Normality: in order to test the normal distribution of data, KolmogrovSmirnov test was used. The test shows that the data of this study are normally distributed as the result of the test was above $5 \%$ as follows:

Table 2

Test for Normality

\begin{tabular}{lccc}
\hline The Test & \multicolumn{3}{c}{ The Fields } \\
\cline { 2 - 4 } & $\begin{array}{c}\text { Confidence Crisis in } \\
\text { the Programs and } \\
\text { Operations }\end{array}$ & $\begin{array}{c}\text { Confidence Crisis in } \\
\text { Service Providers }\end{array}$ & $\begin{array}{c}\text { Confidence Crisis in } \\
\text { Protection and } \\
\text { Security }\end{array}$ \\
\hline $\begin{array}{l}\text { Kolmogorov- } \\
\text { Smirnov }\end{array}$ & 1.591 & 1.265 & 1.666 \\
\hline
\end{tabular}

2. Part Two: The Characteristics of the Study Sample

The study sample was grouped with relation to four main characteristics: academic degree, occupation, experience and IT training, as shown in the following table:

Table 3

Frequency and Percent of the Four Sample Characteristics

\begin{tabular}{|c|c|c|c|}
\hline & Frequency & Percent & Cumulative Percent \\
\hline \multicolumn{4}{|l|}{ Academic Degree: } \\
\hline Diplomat & 48 & $46.20 \%$ & $46.20 \%$ \\
\hline Bachelor & 44 & $42.30 \%$ & $88.50 \%$ \\
\hline Master & 12 & $11.50 \%$ & $100 \%$ \\
\hline $\mathrm{PhD}$ & 0 & 0 & \\
\hline Total & 104 & $100 \%$ & \\
\hline \multicolumn{4}{|l|}{ Occupation: } \\
\hline Financial Manager & 48 & $46.20 \%$ & $46.20 \%$ \\
\hline Assistant Financial Manager & 56 & $53.80 \%$ & $100 \%$ \\
\hline Total & 104 & $100 \%$ & \\
\hline \multicolumn{4}{|l|}{ Experience: } \\
\hline Less than 3 years & 20 & $19.20 \%$ & $19.20 \%$ \\
\hline 3 to 6 years & 56 & $53.80 \%$ & $73.10 \%$ \\
\hline 6 to 9 years & 20 & $19.20 \%$ & $92.30 \%$ \\
\hline More than 9 years & 8 & & $100 \%$ \\
\hline Total & 104 & $100 \%$ & \\
\hline \multicolumn{4}{|l|}{ IT Training: } \\
\hline Yes & 12 & $11.50 \%$ & $11.50 \%$ \\
\hline & 92 & $88.50 \%$ & $100 \%$ \\
\hline Total & 104 & $100 \%$ & \\
\hline
\end{tabular}

The table above shows the representativeness of the study sample of the entire population. The statistics show that the majority of the sample have either a Diplomat or a Bachelor degree; a lesser number have a Master degree, and none of the sample is a $\mathrm{PhD}$ holder. This distribution is normal given that the majority of Master degree holder 
have a tendency to carry out their studies, and those who have a $\mathrm{PhD}$ degree opt for academic careers rather than field work.

The occupation is almost equally distributed across the sample; almost half of the informants are Financial Managers and the other half are Assistant Financial Managers. This strengthens the distribution of sample in that it creates a balance in the sample, and, consequently, the results. The study sample is limited to these two ranks due to the fact that the study is concerned with decision-making that is peculiar to the higher management, which is administratively close to these two ranks.

The four levels of experience are equally represented in the sample, which means that the data and results have a high level of credibility.

Last but not least, the percentage of informants who received training is only $11.50 \%$. Having such a small percentage is not counterproductive, given that the majority of employees in these ranks opt for training in finance and administration rather than in Information Technology because the nature of their work necessitates that. However, IT is of vital importance as the world is heading towards a more technology-dependent system.

\section{Part Three: The Fields of Research}

The distribution of scale weight must be presented before tackling the study fields. In this respect, the five-point Likert scale was adopted to give weight to the answers as follows.

\section{Table 4}

The Weight of the Questionnaire Items' Answers

\begin{tabular}{ccccccc}
\hline Values & $\begin{array}{c}\text { Strongly } \\
\text { Agree }\end{array}$ & Agree & Neutral & Disagree & $\begin{array}{c}\text { Strongly } \\
\text { Disagree }\end{array}$ & $\begin{array}{c}\text { Average } \\
\text { Mean }\end{array}$ \\
\hline Weight & 5 & 4 & 3 & 2 & 1 & 3 \\
\hline
\end{tabular}

The average mean was calculated by the sum of all weights (15) and the division on the number of cases (5). This represents the fine line between agreement and disagreement on the questionnaire items.

The study fields were divided into three categories as follows:

1) Confidence crisis in the program and operations offered by the service providers.

2) Confidence crisis in the cloud computing service providers.

3) Confidence crisis in the security and protection offered by cloud computing service providers.

The means and standard deviations of the answers of the sample on the questionnaire items are presented in the table below in order to see the level to which the informants agree or disagree with the questionnaire items.

Insert Table 5 here.

The previous table shows that the average mean of the items related to "the confidence crisis in the programs and operations" is above the average mean of the study (3). This means that the study sample agrees that there is a confidence crisis in the programs and operations offered by cloud computing service providers. This crisis subsumes the lack of confidence in the accounting programs and the processes of payment and data treatment as well as the service providers' databases, which hinders the companies' implantation of cloud computing. The fifth item shows that the main reason behind such lack of confidence is the fact that the cloud computing are not up to par in terms of being underdeveloped and not adequately efficient. 
Table 5

Means and Standard Deviations of Confidence Crisis in the Programs and Operations

\begin{tabular}{|c|c|c|c|}
\hline $\begin{array}{c}\text { Num- } \\
\text { Ber }\end{array}$ & Item & Means & $\begin{array}{l}\text { Standard } \\
\text { Deviation }\end{array}$ \\
\hline 1. & $\begin{array}{l}\text { Company's lack of confidence in the accounting } \\
\text { programs offered by service providers. }\end{array}$ & 3.460 & 1.051 \\
\hline 2. & $\begin{array}{l}\text { Company's lack of confidence in the payment process } \\
\text { offered by service providers. }\end{array}$ & 3.190 & 1.183 \\
\hline 3. & $\begin{array}{l}\text { The process of transferring financial data from one } \\
\text { server to another (internet servers to application servers) } \\
\text { reduces the data credibility. }\end{array}$ & 3.580 & 1.342 \\
\hline 4. & $\begin{array}{l}\text { A Company's lack of confidence in the cloud treatment } \\
\text { processes and financial data storage. }\end{array}$ & 3.350 & 1.392 \\
\hline 5. & $\begin{array}{l}\text { A Company's lack of confidence in the accounting } \\
\text { applications ability to meet all of its needs due to the } \\
\text { applications' underdevelopment. }\end{array}$ & 3.310 & 1.239 \\
\hline 6. & $\begin{array}{l}\text { A Company's lack of confidence in the service providers' } \\
\text { databases. }\end{array}$ & 3.380 & 1.297 \\
\hline & Average & 3.378 & \\
\hline
\end{tabular}

Table 6

Means and Standard Deviations of Confidence Crisis in the Service Providers

\begin{tabular}{|c|c|c|c|}
\hline $\begin{array}{c}\text { Num- } \\
\text { Ber }\end{array}$ & Item & Means & $\begin{array}{l}\text { Standard } \\
\text { Deviation }\end{array}$ \\
\hline 1. & $\begin{array}{l}\text { A Company's lack of confidence in such services due to } \\
\text { its unfamiliarity with such third-party services. }\end{array}$ & 3.500 & 1.254 \\
\hline 2. & $\begin{array}{l}\text { A Company's lack of confidence in the continuity and } \\
\text { consistency of the services offered by the service } \\
\text { providers. }\end{array}$ & 3.270 & 1.201 \\
\hline 3. & $\begin{array}{l}\text { A Company's lack of confidence due to suspected theft, } \\
\text { sale or provision of data to other parties by the service } \\
\text { provider }\end{array}$ & 3.460 & 1.372 \\
\hline 4. & $\begin{array}{l}\text { A Company's lack of confidence in the sincerity of the } \\
\text { service providers' policies. }\end{array}$ & 3.540 & 1.454 \\
\hline 5. & $\begin{array}{l}\text { Company's lack of confidence in the service providers' } \\
\text { tendency to attend to their inquiries and change the } \\
\text { applications as quickly as required. }\end{array}$ & 3.460 & 1.051 \\
\hline 6. & $\begin{array}{l}\text { Company's lack of confidence in their ability to break the } \\
\text { contract and retrieve all the data in case the company } \\
\text { seeks to deal with other service providers. }\end{array}$ & 3.120 & 1.256 \\
\hline & Average & 3.391 & \\
\hline
\end{tabular}

The previous table presents the human rather the technical aspect of cloud computing; it shows the lack of confidence in the cloud computing service providers, which manifests in the high average score surpassing the average of the study by 0.391 . As noted earlier, scores that are higher than the mean are indicative of agreement, and those below it are indicative of disagreement. A Company's lack of confidence in the sincerity of the service providers' policies represents the highest form of confidence crisis, followed by the company's concern about the theft and unauthorized sale of data and its lack of confidence of the service providers' responsiveness to the required changes to the applications. Another form of confidence crisis in the service providers is represented in the fact that the companies are concerned with their ability to safely retrieve their data in case they desire to deal with other service providers. The reasons 
behind such confidence crisis can be attributed to the first item, which has the highest score, i.e., the companies are not highly familiar with having their data in other servers.

Table 7

Means and Standard Deviations of Confidence Crisis in the Security and Protection

\begin{tabular}{|c|c|c|c|}
\hline $\begin{array}{l}\text { Num- } \\
\text { Ber }\end{array}$ & Item & Means & $\begin{array}{l}\text { Std. } \\
\text { deviation }\end{array}$ \\
\hline 1. & $\begin{array}{l}\text { A Company's lack of confidence in the security and } \\
\text { protection measures that is supposed to safeguard the } \\
\text { accounting programs against hacking when modified or } \\
\text { updated. }\end{array}$ & 3.230 & 1.192 \\
\hline 2. & $\begin{array}{l}\text { A Company's lack of confidence in the service providers' } \\
\text { confidentiality and privacy needed for their financial data. }\end{array}$ & 2.960 & 1.230 \\
\hline 3. & $\begin{array}{l}\text { A Company's lack of confidence in the security systems } \\
\text { and the control measures that the service providers take } \\
\text { against the software that can penetrate and hack the } \\
\text { accounting programs and obtain or damage its data. }\end{array}$ & 3.540 & 1.372 \\
\hline 4. & $\begin{array}{l}\text { Company's lack of confidence in the service providers' } \\
\text { ability to properly recover its data in case of any technical } \\
\text { glitch. }\end{array}$ & 3.230 & 1.225 \\
\hline 5. & $\begin{array}{l}\text { Companies lack of confidence in the service providers' } \\
\text { procedure that are supposed to secure the hardware. }\end{array}$ & 3.080 & 1.305 \\
\hline \multirow[t]{2}{*}{6.} & $\begin{array}{l}\text { Company's lack of confidence in the procedures and } \\
\text { regulations that are supposed to prevent the lead of access } \\
\text { data. }\end{array}$ & 3.230 & 1.225 \\
\hline & Average & 3.212 & \\
\hline
\end{tabular}

The average mean of confidence crisis in the security and protection shows a relative agreement of the informant on the items of this section. This means that the companies have a lack of confidence in the protection and security provided by the cloud computing service providers. Such lack of confidence is manifested in the companies' distrust in the security measures taken by the service providers against the software that can hack the accounting programs, and their lack of confidence in the service providers' ability to retrieve their data in case of any glitches. Moreover, the table shows that there is a distrust in the measure taken against the employees to prevent the leakage of data. Finally, the analysis shows that there is a lack of confidence in the safeguard of the service providers' hardware.

\section{Part Four: The Characteristics-related Statistical Differences in the Informants' Responses}

In order to investigate the differences in the informants' responses with regard to their characteristics, two parametric statistical tests were used:

a) Independent-samples T-test: with the two-level categorical questions.

b) One-way Anova: with categorical independent variables (factors) that has two or more different levels.

The results of the two tests show that there are no experience-related statistically significant differences in the responses of the informants. However, the analysis showed that there are some statistically significant differences in the responses of informants with different occupations, academic degree and training as follows:

\subsection{The First Difference: Occupation-related Statistical Differences in the "Confidence Crisis in the Programs and Operations".}

Table 8 shows that there are some statistically significant differences in the responses of the sample to the items of the "confidence crisis in programs and 
operations" construct. On the other hand, table 9 shows that the Assistant Financial Managers have a higher average mean than that of the Financial Managers, which means that the Assistant Financial Managers are more interactive with the items of his construct. This can be attributed to the fact that the Assistant Managers are closer to the field work than the managers.

Table 8

Variance in Occupation and Confidence Crises in Programs and Operations

\begin{tabular}{lcccc}
\multicolumn{1}{c}{ Field } & Variances & T & DF & SIG \\
\hline Confidence Crisis in & Equal & -3.763 & 102 & 0.000 \\
Programs and & Unequal & -3.869 & 97.623 & 0.000 \\
Operations & & & & \\
\hline
\end{tabular}

Table 9

The Results of Descriptive Statistics Grouped by Occupation

\begin{tabular}{llccc}
\hline \multicolumn{1}{c}{ Field } & Occupation & Frequency & Mean & Std. Deviation \\
\hline $\begin{array}{l}\text { Confidence Crisis in } \\
\begin{array}{l}\text { Programs and } \\
\text { Operations }\end{array}\end{array}$ & $\begin{array}{l}\text { Financial Manager } \\
\text { Assistant Financial }\end{array}$ & 48 & 3.181 & 0.392 \\
\hline & Manager & 56 & 3.548 & 0.570 \\
\hline \multicolumn{2}{r}{ Total } & 104 & & \\
\hline
\end{tabular}

4.2. The Second Difference: IT-Training-related Statistical Differences in the "Confidence Crisis in the Security and Protection".

Table 10 shows the statistically significant differences in the responses of informants about the confidence crisis in the security and protection offered by cloud computing service providers. The results show that the individuals who have received IT training have a higher average mean than the informants who have not (table 11). This means that trained informants have a better understanding of the items of this field and have a better ability to respond to these items. This is due to the fact that these informants are familiar with the issues that can risk the security and protection of the systems.

Table 10

Variance in Occupation and Confidence Crisis in the Security and Protection

\begin{tabular}{ccccc}
\hline Field & Variances & T & DF & SIG \\
\hline Confidence Crisis in the & Equal & 3.318 & 102 & 0.001 \\
Security and Protection & Unequal & 2.820 & 12.955 & 0.015 \\
\hline
\end{tabular}

Table 11

The Results of Descriptive Statistics Grouped by IT Training

\begin{tabular}{ccccc}
\hline Field & Occupation & Frequency & Mean & Std. deviation \\
\hline Confidence Crisis in the & Yes & 12 & 3.889 & 0.903 \\
Security and Protection & No & 92 & 3.123 & 0.732 \\
\hline Total & \multicolumn{5}{c}{} \\
\hline 4.
\end{tabular}

4.3. The Third Difference: Academic-Degree-related Statistical Differences in the "Confidence Crisis in the Service Providers".

Table 12 shows the statistically significant differences in the responses of informants about the confidence crisis in the service providers. The analysis shows that the master degree holders have a higher mean average than the rest of the groups. Table 13 shows the numeric differences between each group and the mean of the other two groups combined (referred to as I and J). The subtraction of $(\mathrm{J})$ from (I) gives either positive or negative results. The results of table 13 suggest that the master 
holders have the most consistent responses, which indicate that they have more concerns about the risks when dealing with service providers.

Table 12

Variance in the Academic Degree and Confidence Crisis in the Service Providers

\begin{tabular}{|c|c|c|c|c|c|c|}
\hline Field & $\begin{array}{l}\text { Source of } \\
\text { Variances }\end{array}$ & $\begin{array}{l}\text { Sum of } \\
\text { Squares }\end{array}$ & DF & $\begin{array}{l}\text { Average } \\
\text { Square }\end{array}$ & $\mathbf{F}$ & SIG. \\
\hline \multirow{2}{*}{$\begin{array}{l}\text { Confidence Crisis in } \\
\text { the Service Providers }\end{array}$} & Inter-groups & 5.092 & 2 & 2.546 & \multirow{3}{*}{7.097} & \multirow{3}{*}{0.001} \\
\hline & Intra-groups & 36.229 & 101 & \multirow{2}{*}{0.359} & & \\
\hline Total & & 41.321 & 103 & & & \\
\hline
\end{tabular}

Table 13

The Results of Descriptive Statistics Grouped by Academic Degree

\begin{tabular}{cccccc}
\hline Field & $(\mathbf{I})$ & $(\mathbf{J})$ & Mean $(\mathbf{I})-(\mathrm{J})$ & Std. Error & SIG \\
\hline \multirow{3}{*}{\begin{tabular}{c}
\multirow{2}{*}{ Donfidence Crisis in } \\
the Service Providers
\end{tabular}} & Bachelor & -0.202 & 0.125 & 0.244 \\
& \multirow{2}{*}{ Bachelor } & Master & $-0.722^{*}$ & 0.193 & 0.001 \\
\cline { 2 - 6 } & & Diplomat & 0.202 & 0.125 & 0.244 \\
& \multirow{2}{*}{ Master } & Master & $-0.521^{*}$ & 0.195 & 0.024 \\
\cline { 2 - 6 } & & Diplomat & $0.722^{*}$ & 0.193 & 0.001 \\
& & Bachelor & $0.521^{*}$ & 0.195 & 0.024 \\
\hline
\end{tabular}

\section{Part Five: Hypotheses Testing}

In order to test the hypotheses set for the current study, the researchers used One-Sample T-Test on each sub-hypothesis separately. This was motivated by two main reasons:

1) To gain more precision in identifying the aspects of confidence crisis.

2) The sum of the sub-hypotheses either proves or refute the main study hypothesis.

As mentioned earlier, the main study hypothesis is:

"There is no confidence crisis in the application of cloud computing in the industrial companies in Jordan".

And the study sub-hypotheses are as follows:

1) There is no confidence crisis in the program and operations offered by the service providers to apply cloud computing in the industrial companies in Jordan.

2) There is no confidence crisis in the cloud computing service providers in the industrial companies in Jordan.

3) There is on confidence crisis in the security and protection offered by cloud computing service providers in the industrial companies in Jordon.

Table 14

Hypotheses-Testing

\begin{tabular}{|c|c|c|c|c|c|}
\hline Hypotheses & $\begin{array}{c}\text { Tabulated } \\
\text { T-value }\end{array}$ & $\begin{array}{l}\text { Calculated } \\
\text { T-value }\end{array}$ & SIG. & $\begin{array}{c}\text { Average } \\
\text { mean }\end{array}$ & Result \\
\hline \multicolumn{6}{|c|}{ Sub-Hypotheses } \\
\hline $\begin{array}{l}\text { No Confidence Crisis in } \\
\text { the Programs and Operations }\end{array}$ & 1.960 & 7.324 & 0.000 & 3.278 & Refuted \\
\hline $\begin{array}{l}\text { No Confidence Crisis in } \\
\text { the Service Providers }\end{array}$ & 1.960 & 6.296 & 0.000 & 3.391 & Refuted \\
\hline $\begin{array}{l}\text { No Confidence Crisis in } \\
\text { the Security and Protection }\end{array}$ & 1.960 & 2.739 & 0.007 & 3.212 & Refuted \\
\hline \multicolumn{6}{|c|}{ The Main Hypothesis } \\
\hline $\begin{array}{l}\text { No Confidence Crisis in th } \\
\text { Computing }\end{array}$ & Applicatio & of Cloud & & Refuted & \\
\hline
\end{tabular}


The null hypothesis is refuted if the Calculated T-value is higher that the Tabulated T-value and the level of significance (SIG) is less than 5\% (El-Batsh \& Abou Zina, 2007, p. 192). Therefore, on the basis of the results in the previous table, the three null sub-hypotheses will be refuted; instead, three alternative hypotheses will be accepted as follows:

1) There is a confidence crisis in the program and operations offered by the service providers to apply cloud computing in the industrial companies in Jordan.

2) There is a confidence crisis in the cloud computing service providers in the industrial companies in Jordan.

3) There is a confidence crisis in the security and protection offered by cloud computing service providers in the industrial companies in Jordan.

Since the three null sub-hypotheses are refuted; the main null hypothesis is also refuted, and the alternative hypothesis is accepted as follows:

"There is a confidence crisis in the application of cloud computing in the industrial companies in Jordan".

The study main results can be concluded as follows:

1. There is a Confidence Crisis in the Application of Cloud Computing in the Industrial Companies in Jordan (the main hypothesis). The categories of this crisis are:

1) Confidence crisis in the program and operations offered by the service providers (the first sub-hypothesis). The aspects of this category are:

a) A Company's lack of confidence in the process of transferring financial data from one server to another (internet servers to application servers).

b) A Company's lack of confidence in the accounting programs offered by service providers.

c) A Company's lack of confidence in the service providers' databases.

d) A Company's lack of confidence in the Cloud treatment processes and financial data storage.

e) A Company's lack of confidence in the accounting applications ability to meet all of its need due to its underdevelopment.

f) A Company's lack of confidence in the payment process offered by service providers.

2) Confidence crisis in the Cloud Computing service providers in the industrial companies in Jordan (the second sub-hypothesis). The aspects of this category are:

a) A Company's lack of confidence in the sincerity of the service providers' policies.

b) A Company's lack of confidence in such services due to its unfamiliarity with such third-party services.

c) Company's lack of confidence due to suspected theft, sale or provision of data to other parties by the service provider.

d) A Company's lack of confidence in the service providers' tendency to attend to their inquiries and change the applications as quickly as required.

e) A Company's lack of confidence in the continuity and consistency of the services offered by the service providers.

f) A Company's lack of confidence in their ability to break the contract and retrieve all the data in case the company seeks to deal with other service providers.

3) Confidence crisis in the security and protection measures taken by Cloud Computing service providers in the industrial companies in Jordan (the third sub-hypothesis). The aspects of this category are: 
a) A Company's lack of confidence in the security and protection measures that is supposed to safeguard the accounting programs against hacking when modified or updated.

b) A Company's lack of confidence in the service providers' ability to properly recover its data in case of any technical glitch.

c) A Company's lack of confidence in the procedures and regulations that are supposed to prevent the lead of access data.

d) A Companies lack of confidence in the service providers' procedure that are supposed to secure the hardware.

\section{There are Statistically Significant Variances in the Study Fields the Sample} Characteristics, as Shown in the Following Table:

\section{Table 15}

The Statistically Significant Variances in the Study Fields and the Sample Characteristics

\begin{tabular}{|c|c|c|c|c|c|}
\hline $\begin{array}{l}\text { Num- } \\
\text { ber }\end{array}$ & Field & & $\begin{array}{c}\text { Sample } \\
\text { Characteristics }\end{array}$ & $\begin{array}{c}\text { In favour } \\
\text { of }\end{array}$ & Interpretation \\
\hline 1. & $\begin{array}{l}\text { Confidence Crisis } \\
\text { in the Programs } \\
\text { and Operations }\end{array}$ & & $\begin{array}{l}\text { Occupation (fi- } \\
\text { nancial manager, } \\
\text { assistant financial } \\
\text { manager) }\end{array}$ & $\begin{array}{l}\text { Assistant } \\
\text { financial } \\
\text { manager }\end{array}$ & $\begin{array}{l}\text { Assistants are } \\
\text { more interactive } \\
\text { with the items of } \\
\text { this field. }\end{array}$ \\
\hline 2. & $\begin{array}{l}\text { Confidence crisis } \\
\text { in the security and } \\
\text { protection }\end{array}$ & With & Training (yes/no) & $\begin{array}{l}\text { IT- } \\
\text { trained } \\
\text { informan } \\
\text { ts }\end{array}$ & $\begin{array}{l}\text { IT-trained inform- } \\
\text { ants have a better } \\
\text { under-standing of } \\
\text { the items of this } \\
\text { field and have } \\
\text { more capacity to } \\
\text { respond to them. }\end{array}$ \\
\hline 3. & $\begin{array}{l}\text { Confidence crisis } \\
\text { in the service } \\
\text { providers }\end{array}$ & & $\begin{array}{l}\text { Academic degree } \\
\text { (Diplomat, Bache- } \\
\text { lor, Master) }\end{array}$ & $\begin{array}{l}\text { Master } \\
\text { holders }\end{array}$ & $\begin{array}{l}\text { Master holders are } \\
\text { more consistent in } \\
\text { their responses are } \\
\text { apparently more } \\
\text { concerned about } \\
\text { the risk resulting } \\
\text { from dealing with } \\
\text { service providers }\end{array}$ \\
\hline
\end{tabular}

\section{RECOMMENDATIONS}

The researchers recommend the following:

1. Cloud Computing service providing companies should promote and encourage the use and mechanisms of Cloud Computing and the security and protection measures to the systems, applications and data at their disposal so that the companies can get rid with such lack of confidence.

2. Guiding the financial managers and assistant financial managers to receive IT training due to its importance in developing and improving the accounting businesses, and due to the positive impact it has on the confidence in electronic businesses and the most recent technological advances.

3. Conducting more research studies on the factors that prevented the industrial companies in Jordan from having confidence in the implementation of cloud computing. 


\section{REFERENCES}

Abid, M. H., Jan, F., Mustafa, T., \& Faridi, M. S. (2012). Cloud computing: A general user's perceptions and security issues at Universities of Faisalabad, Pakistan. International Journal of Computer Science Issues, 9(5), 375-380. Retrieved from https://www.ijcsi.org/papers/IJCSI-9-5-2-375-380.pdf.

Al-Fadl, A. A. (2016). The efficiency of cloud computing in supporting banking databases. Al-Qadisiyah Journal of Economic and Administrative Sciences, 18(3), 246268. Retrieved from https://www.iasj.net/iasj?func=fulltext\&aId $=113471$.

Alhammadi, A., Stanier, C., \& Eardley, A. (2015). The determinants of cloud computing adoption in Saudi Arabia. Computer Science \& Information Technology, 55-67. Retrieved from https://www.researchgate.net/publication/299867345_The_ Determinants_of_Cloud_Computing_Adoption_in_Saudi_Arabia.

Aljabre, A. (2012). Cloud computing for increased business value. International Journal of Business \& Social Science, 3(1), 234-239. Retrieved from http://ijbssnet.com/journals/Vol_3_No_1_January_2012/26.pdf.

Alkhater, N., Wills, G., \& Walters, R. (2014, December). Factors influencing an organisation's intention to adopt cloud computing in Saudi Arabia (pp. 1040-1044). 2014 IEEE $6^{\text {th }}$ International Conference on Cloud ComputingTechnology\& Science (CloudCom). Retrieved from https://eprints.soton.ac.uk/372717/1/ my\%2520paper.pdf.

Al-ulaymi, T., \& Al-ulaymi, M. (2014, March 25-27). How to benefit from cloud computing applications in the information services provision in the United Arab Emirates? (pp. 1-14). The SLA-AGC 20 $0^{\text {th }}$ AnnualConference, Doha, Qatar. Retrieved from https://www.qscience.com/docserver/fulltext/qproc/2014/1/qproc.2014.gsla.6 .pdf.

Bansode, S. Y., \& Pujar, S. M. (2012). Cloud computing and libraries. DESIDOC Journal of Library \& Information Technology, 32(6), 506-512. Retrieved from https://publications.drdo.gov.in/ojs/index.php/djlit/article/view/2848/1392.

Bhour, K. M. S. (2016). The presence of factors influencing the adoption and application of cloud computing in the government institution from the higher management perspective. Master's thesis, Islamic University Gaza, Palestine. Retrieved from https://iugspace.iugaza.edu.ps/handle/20.500.12358/20793.

Budņiks, L., \& Didenko, K. (2014). Factors determining application of cloud computing services in Latvian SMEs. Procedia-Social \& Behavioral Sciences, 156, 7477. Retrieved from https://www.researchgate.net/publication/275544705_ Factors_Determining_Application_of_Cloud_Computing_Services_in_Latvian_ SMEs.

Chen, N. C. (2009). A feasibility study of the adoption of cloud computing in the development of information system. Master's thesis, The University of Sheffield, Sheffield, UK.

El-Batsh, M. W., \& Abou Zina, F. K. (2007). Research methodology "research design and statistical analysis" (1 ${ }^{\text {st }}$ ed.). Amman, Jordan: Dar al Masira Publishing House.

Elena, G., \& Johnson, C. W. (2015). Factors influencing risk acceptance of cloud computing services in the UK government. International Journal on Cloud Computing: Services \& Architecture (IJCCSA), 5(2/3), 1-16. Retrieved from https://pdfs.semanticscholar.org/3382/4579a3f3b072e3e88a6ddca183057f42cb a9.pdf. 
Gupta, P., Seetharaman, A., \& Raj, J. R. (2013). The usage and adoption of cloud computing by small and medium businesses. International Journal of Information Management, 33(5), 861-874. Retrieved from https://www.researchgate.net/ publication/259123423_The_usage_and_adoption_of_cloud_computing_by_sm all_and_medium_businesses.

Hashemi, S. (2013). Cloud computing technology: Security and trust challenges. International Journal of Security, Privacy \& Trust Management (IJSPTM), 2(5), 1-7. Retrieved from https://pdfs.semanticscholar.org/b2b7/69db7ceea32793d7 c3680a15edaa294695ae.pdf.

Hashim, H. S., \& Hassan, Z. B. (2015, August). Factorsthat influence the users' adoption of cloud computing services at Iraqi universities: An empirical study. Australian Journal of Basic \& Applied Sciences, 9(27), 379-390. Retrieved from https://pdfs.semanticscholar.org/234f/86e672e6d16c3c434b90c71dc17e80dde0 09.pdf.

Hsu, C. L., \& Lin, J. C. C. (2016). Factors affecting the adoption of cloud services in enterprises. Information Systemse e-Business Management, 14(4), 791-822. Retrieved from https://link.springer.com/content/pdf/10.1007\%2Fs10257-015-03009.pdf.

Hurwitz, J., Bloor, R. \& Kaufman, M. (2010). Cloud computing for dummies. Indiana: WileyPublishing, Inc. Retrieved from: https://fit.mta.edu.vn/files/ DanhSach/_R_Book_HP_cloudcomputingfordummies.pdf.

Hussein, A., \& Mohamed, O. (2015). Cloud computing and its effect on performance excellence at higher education institutions in Egypt (an analytical study). European Scientific Journal, (Special edition), 163-176. Retrieved from http:/ / eujournal.org/index.php/esj/article/download/6528/6253.

Jelonek, D., \& Wyslocka, E. (2014). Barriers to the development of cloud computing adoption and usage in SMEs in Poland. Advances in Information Science \& Applications, 1, 128-133. Retrieved from http://www.inase.org/library/ 2014/santorini/bypaper/COMPUTERS/COMPUTERS1-17.pdf.

Kaushik, A., \& Kumar, A. (2013). Application of cloud computing in libraries. International Journal of Information Dissemination \& Technology, 3(4), 270-273. Retrieved from https://pdfs.semanticscholar.org/6092/71897acf17e74b546ecc8 e1f1e9faac116bc.pdf.

Majhi, S., Meher, S., \& Maharana, B. (2015). Awareness and usage of cloud computing application among LIS professionals: A case study of 17 Indian University Libraries. Library Philosophy and Practice (e-Journal). Retrieved from http://digitalcommons.unl.edu/libphilprac/1280/.

Mell, P., \& Grance, T. (2011). The NIST definition of cloud computing (pp. 1-3). Computer Security Division, Information Technology Laboratory, National Institute of Standards \& Technology, Gaithersburg, MD. 20899-8930. Retrieved from: https://nvlpubs.nist.gov/nistpubs/legacy/sp/nistspecialpublication800-145.pdf.

Mohammed, D. (2011, May 26). Security in cloud computing: An analysis of key drivers and constraints. Information Security Journal: A Global Perspective, 20(3), 123-127. Retrieved from https://www.tandfonline.com/doi/abs/10.1080/19393555. 2010.544704.

Office of Jordan Industrial Estates Corporation. (2017). Statistics. Irbid-Jordan.

Pawar, N., \& Udgir, V. (2016, June). A comparative study of data security in cloud computing environment. International Journal of Science, 2(3), 1-6. Retrieved from http:/ /ijoscience.com/wp-content/uploads/2016/06/ nikit-paper.pdf. 
Qurayqaa, M. Z. H. (2014). Effectiveness of a training program for the use of cloud computing applications in the development of e-learning skills among technology teachers. Master's thesis, Islamic University, Gaza, Palestine. Retrieved from http://library.iugaza.edu.ps/thesis/115027.pdf.

Ren, K., Wang, C., \& Wang, Q. (2012). Security challenges for the public cloud. IEEE Internet Computing, 16(1), 69-73. Retrieved from https://ieeexplore.ieee.org/ document/6123700.

Romney, M. B., \& Steinbart, P. J. (2012). Accounting information systems (12 ${ }^{\text {th }}$ ed.). Boston: Pearson.

Saleem, T. A. (2016). Cloud computing between theory and Practice. Cybrarians Journal, 42, 1-21. Retrieved from http://www.journal.cybrarians.info/images/042/ Cybrarians_Journal_042_Papers_07.pdf.

Sayed, R. F. A. (2013). Open source cloud computing systems: Comparative analytical study. Iraqi Journal of Information Technology, 5(2), 17-41. Retrieved from https://www.academia.edu/5151512.

Sharif, W. A., Hassan, M. A., Kurdi, S. A., \&Yaafi, W. A. (2013). Effectiveness of the knowledge cloud containers and its role in supporting e-learning systems and development of scientific research in Saudi Arabia (pp. 1-24). The Third International Conference for E-learning and Distance Education. Riyadh. Retrieved from: https://kenanaonline.com/files/0100/100412/rp50.pdf.

Sun, D., Chang, G., Sun, L., \& Wang, X. (2011). Surveying and analyzing security, privacy and trust issues in cloud computing environments. Procedia Engineering, 15, 2852-2856. Retrieved from https://ac.els-cdn.com/S1877705811020388/1-s2.0S1877705811020388-main.pdf?_tid=050d8f7a-0c77-4652-a844-09d020ede703\& acdnat $=1534192724 \_b 8654 c c 6 e 02 b f 1 b 82 c a a a 0 e c c 0 f 5379 c$.

Tarmidi, M., Rasid, S. Z. A., Alrazi, B., \& Roni, R. A. (2014). Cloud computing awareness and adoption among accounting practitioners in Malaysia. ProcediaSocial \& Behavioral Sciences, 164, 569-574. Retrieved from https://core.ac.uk/download/pdf/42980639.pdf.

Turab, N. M., Taleb, A. A., \& Masadeh, S. R. (2013). Cloud computing challenges and solutions. International Journal of Computer Networks \& Communications, 5(5), 209216. Retrieved from http:// airccse.org/journal/cnc/5513cnc15.pdf.

Zhygalova, A. (2013). Perceived value of cloud based information systems. Case: Accounting Information Systems. Master's Thesis, Aalto University. Retrieved from https:/ /aaltodoc.aalto.fi/bitstream/handle/123456789/12746/hse_ethesis_1352 5.pdf?sequence $=1 \&$ is Allowed $=\mathrm{y}$.

Zissis, D., \&Lekkas, D. (2012). Addressing cloud computing security issues. Future Generation Computer Systems, 28(3), 583-592. Retrieved from https://www.sciencedirect.com/science/article/pii/S0167739X10002554. 